\title{
Biomedical health monitoring system design and analysis
}

\author{
Nur Athilah Abdul Rahman, Asral Bahari Jambek \\ School of Microelectronic Engineering, Universiti Malaysia Perlis, Malaysia
}

\begin{tabular}{l} 
Article Info \\
\hline Article history: \\
Received Oct 11, 2018 \\
Revised Dec 10, 2018 \\
Accepted Dec 22, 2018 \\
\hline Keywords: \\
Airflow sensor \\
Arduino Uno \\
Body temperature \\
ECG \\
E-Health Shield V2.0 \\
GSR
\end{tabular}

\begin{abstract}
E-Health remote monitoring systems have bloomed rapidly with a myriad of applications. This paper discusses a design of a remote monitoring device for biomedical field. Four biomedical sensors which are electrocardiography (ECG), airflow, galvanic skin response and temperature with two boards which are the e-Health Shield Board V2.0 and Arduino Uno Board are used. The results show satisfactory output for each experiment using two test subjects. The device able to achieve high accuracy where percentage of temperature difference is less than $1 \%$ compared to the commercial devices with an average power consumption of each working sensor on board is $\leq 9 \mathrm{~W}$.
\end{abstract}

Copyright $@ 2019$ Institute of Advanced Engineering and Science. All rights reserved.

\section{Corresponding Author:}

Nur Athilah Abdul Rahman,

School of Microelectronic Engineering, Universiti Malaysia Perlis,

Pauh Putra Campus, 02600 Arau, Perlis, MALAYSIA.

Email: n.athilah@yahoo.com.my

\section{INTRODUCTION}

E-Health, as stated by the World Health Organisation (WHO), is the application of both information and communication technology for research and tracking diseases to monitor public health [1]. e-Health monitoring is widely used in all age groups ranging from infants in [2], [3], to elders in [4]. Other research applied it in diseases monitoring as in [5] or the subject's condition in certain activities such as fire-fighters in [6], or astronauts in [7], drivers in [8] or physical activity monitoring in [9].

All the monitoring systems equipped with a node or more than one node as a front-end device is called Body Sensor Networks (BSN) or Wireless Body Area Networks (WBAN) [8]. The sensors collect the body signals, pre-processed by the conditioning circuit and next digitised by Analog to Digital Converter (ADC) and sampled by a microcontroller before being wirelessly transmitted to the central point for data analysis or display purposes. In [10], $21 \%$ of health remote monitoring patients are not willing to use the system device. Redundant wiring is one of the reasons in [2] as it leads to obstruction of mobility, hazard and discomfort for the babies. While in $[10,11]$, the efficiency of the device also needs to be considered and has yet to be analysed. Lower cost devices [12] that are more compact and [11] and have low power consumption for ease of mobility are preferred.

To overcome the challenges, researches such as remote bio-signal monitoring in [2], [13] operates at small size, is portable and wearable on the chest or the arm respectively. Apart from that, the efficiency of the node discussed in [13] by adding SD card for offline data record.

This paper reviews the available designs of e-health and discusses the importance in each front-end device design. An e-Health shield board V2.0 connected with an Arduino Uno board was used to test four biomedical sensors comprising an Electrocardiography (ECG) sensor, Airflow sensor, Galvanic Skin Response (GSR) sensor and Temperature Sensor. Each sensor data is displayed in a graph against time in Section IV. The available research on e-health devices is reviewed in Section II, while Section III discusses the methodology on how e-Health Shield board V2.0 functioned. The result is presented in Section IV, and the paper is concluded in Section V. 
Paper in [13] introduces a non-contact Electrocardiogram (ECG) electrodes used in a wearable arm band that monitored wirelessly on mobile phone. As shown in Figure 1, the $48 \mathrm{~mm}$ diameter size sensor node consist of 3 lead conductive type electrodes to acquire the ECG signal, pre-processing conditioning circuit, an 8-bit Lilypad Arduino microcontroller and Bluetooth as the communication. The microcontroller memory supported with $16 \mathrm{kB}$ flash and only $1 \mathrm{kB}$ SRAM. An additional built-in 10-bit ADC is used to convert the analog signals. The system is validated by comparing with normal wet-electrode system and then peak detection testing while undergoes different activities.

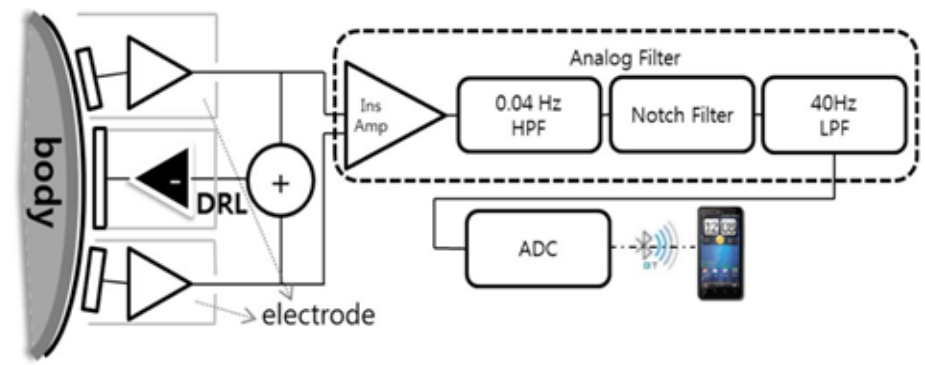

Figure 1. Show the non-contact ECG arm band block diagram [13]

In [14] the system proposed is focused on real time monitoring and alarming system from various sensors for patient health. The system node or the sensing unit as shown in Figure 2 consist of a medical sensor set which are 5 leads ECG, blood pressure, temperature and SpO2 sensors, an 8-bit RISC AtMega2560 microcontroller and a Bluetooth communication system. The microcontroller provides $256 \mathrm{kB}$ flash and $8 \mathrm{kB}$ SRAM memory also built in 10-bit ADC. The experimental test result show that the system is reliable and good in accuracy for remote monitoring after compared with hospital medical device.

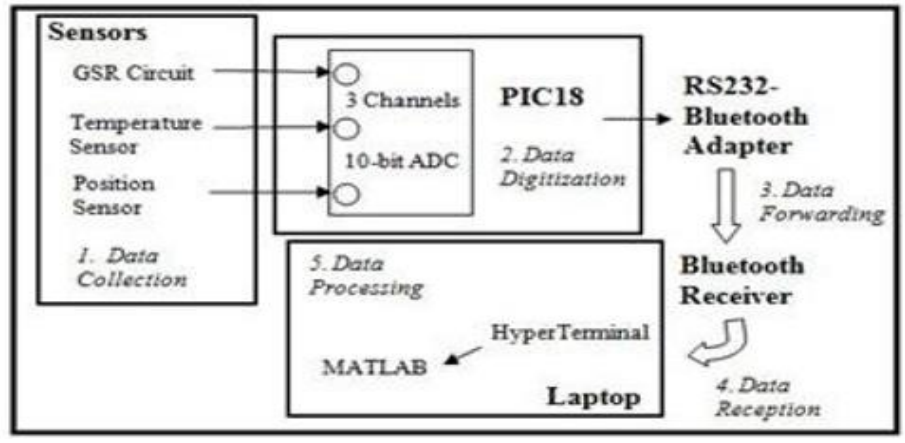

Figure 2. Show the sensing unit block diagram from paper in [14]

An epileptic seizure detection hardware design is proposed in [15]. The system which traditionally measured by the EEG sensor is substitute by monitoring three sensors output that is Galvanic Skin Response (GSR), MCP9701A an analog thermal sensor and a rotational sensor as illustrated in Figure 3. The implemented hardware is composed of these sensors, a PIC18F8722 microcontroller and Bluetooth communication. The 8bit microcontroller completed with $128 \mathrm{kB}$ flash, $4 \mathrm{kB}$ RAM memory and built in 10-bit microcontroller. Temperature sensor result are verified by testing on ambient temperature by giving constant value $75^{\circ} \mathrm{F}$, the rotational sensor also gives concurrent to angle of rotation, meanwhile the GSR results corresponding to the emotion of the subject. Figure 3 Show the hardware design block diagram.

Paper in [16] discusses a sensor node design that able to measure emotions through the changes in autonomic nervous system using various sensors. The system as shown in Figure 4 consists of Galvanic Skin Resistance (GSR), Blood Volume Pulse (BVP) and LM35 temperature sensors in data acquisition part. While a 16-bit MSP430F2013 microcontroller composed of 2kB with additional 256B flash memory, 128B RAM memory and sigma delta type 16 bit built in ADC. The experimental setup is set to let subjects listen to different songs in order to obtain different emotions. 


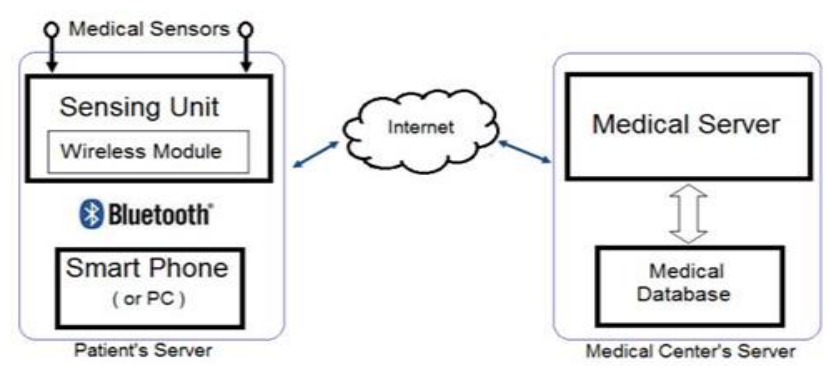

Figure 3. Show the hardware design block diagram in [15]

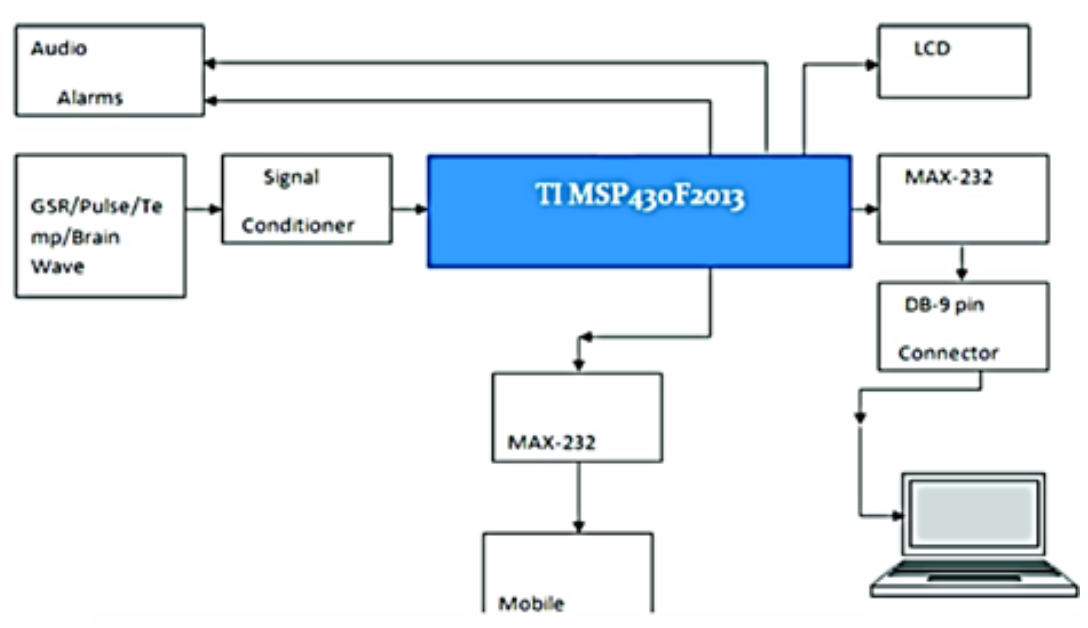

Figure 4. Show the emotion detection sensor node block diagram in [16]

In [17], a distributed sensor node namely iNODE are design for real time monitoring of Parkinson Disease (PD) patient during rehabilitation. The flexible PCB board of iNODE that are bendable and can be fold to a compact cube of size $20 \mathrm{~mm} 3$ consist of two sensors that is Force Sensitive Resistor (FSR) for locomotion measurement at the foot and Respiratory Inductive plethysmography (RIP) for breathing detection wear on the abdomen, a 16-bit MSP430F2618 microcontroller as the processing part comes with $48 \mathrm{kB}$ flash and 10kB RAM memory and 12 bits built in ADC are as shown in Figure 5. The system is small and portable at the weight of $3 \mathrm{~g}$ and average current consumption of $120 \mu \mathrm{A}$ at $3.6 \mathrm{~V}$ for the RIP iNODE.

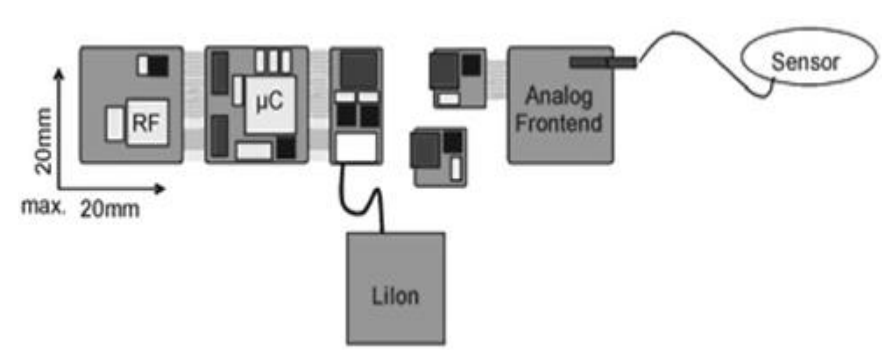

Figure 5. Show the iNODE block diagram design in [17]

Table 1 summarized the literature review discussed in section III of this paper. Majority of these papers targeted a real time monitoring, wearable, portable and accurate sensor node for e-Health monitoring. The papers researched in year range from 2011 to 2016 for the latest hardware design implementation in ehealth sensor node. In comparison, all of this paper design in sensor node still shares the same processes as explained in Section 1. 
Table 1. Comparison Table

\begin{tabular}{|c|c|c|c|c|c|c|c|}
\hline \multirow[t]{2}{*}{ PAPER } & \multirow[t]{2}{*}{ YEAR } & \multirow[t]{2}{*}{ SENSOR } & \multicolumn{5}{|c|}{$\mathrm{MCU}$} \\
\hline & & & PROCESSOR & SIZE & \multicolumn{2}{|c|}{ MEMORY } & $\mathrm{ADC}$ \\
\hline [13] & 2016 & $\begin{array}{l}\text { ECG } 2 \text { conductive } \\
\text { electrode }\end{array}$ & $\begin{array}{l}\text { Lilypad } \\
\text { arduino }\end{array}$ & 8-bit & $16 \mathrm{~KB}$ & $\begin{array}{c}1 \mathrm{~KB} \\
\text { (SRAM) }\end{array}$ & SAR 10 bit \\
\hline [14] & 2016 & $\begin{array}{c}\text { ECG (5 Leads), BP, } \\
\text { Temperature (LM35), } \\
\text { SpO2 (o2 saturation \& } \\
\text { heartbeat) }\end{array}$ & $\begin{array}{c}\text { Atmel Mega } \\
2560\end{array}$ & $\begin{array}{l}\text { 8-bit } \\
\text { RISC }\end{array}$ & $256 \mathrm{kB}$ & $\begin{array}{c}8 \mathrm{kB} \\
(\mathrm{SRAM})\end{array}$ & SAR 10 bit \\
\hline$[16]$ & 2014 & $\begin{array}{l}\text { GSR, temperature, heart } \\
\text { beat }\end{array}$ & $\begin{array}{c}\text { TI } \\
\text { MSP430F2013 }\end{array}$ & 16-bit & $\begin{array}{l}2 \mathrm{~KB}+ \\
256 \mathrm{~B}\end{array}$ & 128B & Sigma-delta 16 bit \\
\hline [17] & 2011 & $\begin{array}{c}\text { FSR, respiratory } \\
\text { inductive } \\
\text { plethysmography (RIP) }\end{array}$ & MSP430F161 & 16-bit & $48 \mathrm{~KB}$ & $10 \mathrm{~KB}$ & SAR 12 bit \\
\hline
\end{tabular}

\section{RESEARCH METHOD}

\subsection{Hardware}

This section introduces the bio-signal monitoring system assisted by e-Health Sensors Platform V2.0 from Cooking Hacks, open hardware division department of Libedium Communication Distribution [18]. The system consists of an Arduino Uno board, e-Health Shield platform board and four bio-sensors which were Electrocardiogram (ECG), Airflow, Galvanic Skin Response (GSR) and temperature as shown in the block diagram in Figure 6. These sensors acquired the bio-signals simultaneously and were pre-processed by the eHealth shield board and Arduino Uno board before being transferred serially through USB port to PC for data display and analysis.

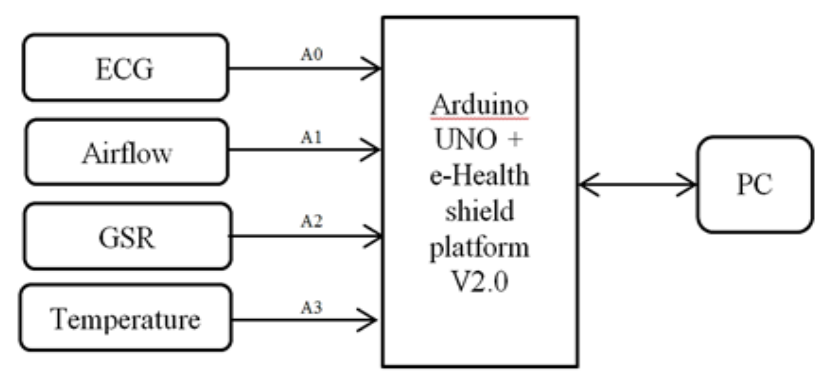

Figure 6. Show the block diagram for e-Health monitoring design

The controller part of the bio-signal monitoring system is based on the Arduino Uno board. The ATmega328P based microcontroller differs from other Arduino boards by the USB to serial driver chip which is an Atmega16U2 instead of FTDI chip. The board is also geared with Rx/Tx LED that blinks when data transmission occurs via USB to serial chip. Other information is described in [20].

The e-Health shield board is designed to be attached to microcontroller boards which are Arduino Uno or Raspberry Pi for biomedical monitoring and application purposes [18]. The board can connect about ten sensors and pre-processed each signal by analogue circuitry respectively. The sensors and other functions of the shield board are listed in [18]. ECG signals are detected from the electrical and muscular activity of the heart which is recorded by 3-lead electrodes made of silver/silver chloride $(\mathrm{Ag} / \mathrm{AgCl})$ [18]. The electrodes consisted of $+v e,-v e$ and Neutral polarity and placed accordingly to each colour as described in tutorial in [18]. The wire is then connected to the pluggable screw terminal on the shield board to send raw sensor data to the analogue conditioning circuit pre-processes the sensor signals on the shield board and then digitised by Analog pin ' 0 ' (A0) from Arduino Uno board before being transmitted to PC. The range output is between 0 to $5 \mathrm{~V}$.

Breathing or airflow sensor sensed by thermal airflow coming out from the nostril using a sensor. This sensor consists of a cannula/holder that envelope a thermistor sensor inside and holds two prongs on top of it for collecting air under the nostril. The wire polarity is differentiated by the colour of the flexible thread; red for positive and blue for negative to be fixed on the pluggable screw terminal [18]. Similar to ECG, the sensor pre-processed is digitised at Analog pin ' 1 ' (A1). The value is displayed between the ranges of 0 to 1024 digital voltages. 
Galvanic Skin Response (GSR) from Cooking Hacks measures skin resistance between two sensitive points which detected by a small site of $\mathrm{Ag} / \mathrm{AgCl}$ equipped with a Velcro strap to maintain the sensor position on the fingers. The sensor has no polarity and is directly connected to pluggable screw terminal and digitised by Analog pin '2' (A2). The sensor could be calibrated to enhance its accuracy as explained in Cooking Hacks tutorial website. The sensor output could be displayed in resistance value or conductance value.

The temperature sensor measures the temperature of the skin in contact with the surface plate at any temperature-sensitive body part. Instead of lead cable like other sensors, this sensor uses a mono audio connector to transmit the data to one of the shield board pins in [15].

The sensor precision could be obtained through a calibration process as in the tutorial in [20]. Arduino Uno Analog digitises data from the shield board to Digital converter (ADC) from Analog pin '3' (A3). The output data voltage ranges between 0 to $5 \mathrm{~V}$ after being converted to an analogue value via c- program.

\subsection{Software}

This system used two types of software to manipulate the data output other than Arduino IDE for compiling c-code into Hex file and next downloading the Hex file into Arduino board. The two software is working together to process the output data which are Realterm and KST2 for real-time data plotting

1. Realterm

This software saves all the output data transmitted serially into one text file. This file is then used in KST2 to be generated into graph against time [21].

2. $\mathrm{KST} 2$

KST2 is open software that generates data from text file into a graph against time. The data generated can be monitored in a live feed of data saved from Realterm [22].

\section{RESULTS AND ANALYSIS}

In this section, each sensor as setup as show in Figure 7 is tested and displayed in Arduino IDE serial monitor or KST2 real-time monitoring software. Sensor data are then compared and verified with existing commercial devices. All of the sensors are then tested simultaneously for verifying the system's ability.

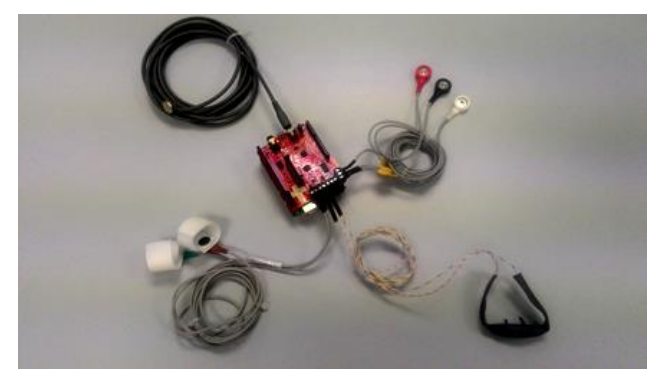

Figure 7. Effects of selecting different switching under dynamic condition

The ECG voltage signal is plotted using Realterm and KST2 software as illustrated in Table 2. Two activities were conducted on two subjects in a relaxed state and after running. During the relaxed state, both subjects R- peak in the 100 second period between 2 to 3 times each. Meanwhile, after the run state, the Rpeaks observed in both subjects increased to 3 to 4 times in each period. Signals from Subject 2 which are taken in a laying position are more stable compared to Subject 1 that was in a sitting position. Slight moves can affect the ECG signals.

In Table 3, three breathing activities were recorded from Subject 1 and Subject 2. Normal breathing is while in a relaxed condition and without any time constraint. The controlled breathing was carried out by timing the inhaling and exhaling of the subject every three seconds. At maximum exhalation, the subjects need to take a deep breath before exhaling to their maximum. In Table 3, in the normal state, both subject breathings produced low voltage output which is less than 100 digital volts compared to controlled breathing activity where the breathing increased up to 100 digital volts. For maximum exhalation results, both readings peaked above 250 digital volts. The sensor works properly when detecting thermal from exhaled air, however, when the thermistor at the prong touched the skin, the result become invalid because the skin temperature was detected with the breath temperature. Thus, the prong must be careful not to touch the skin. 
Table 2. Show ECG signal results from two subjects at two different activities

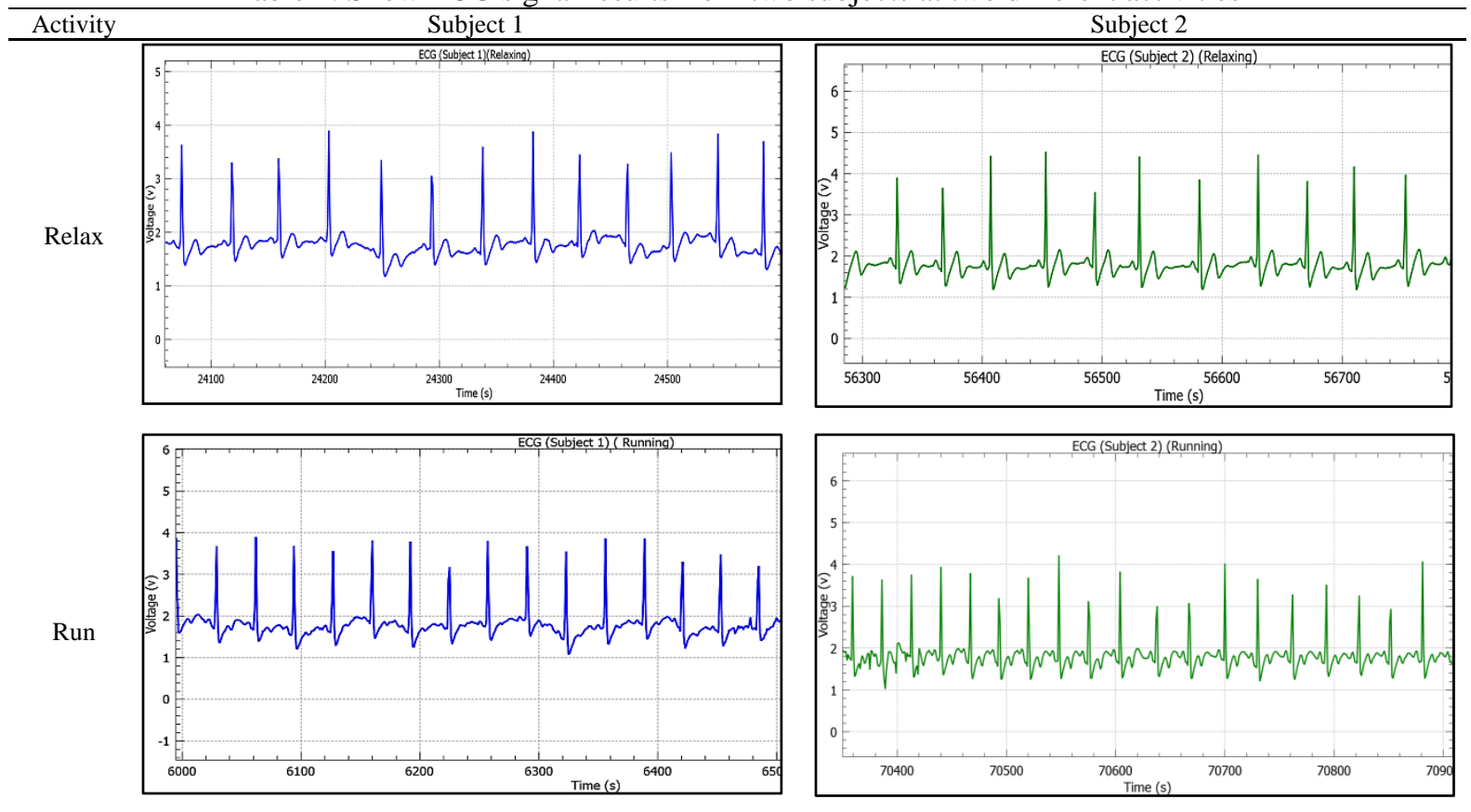

Table 3. Show the airflow graph of digital voltage output against time (s) for different activities of two different subjects

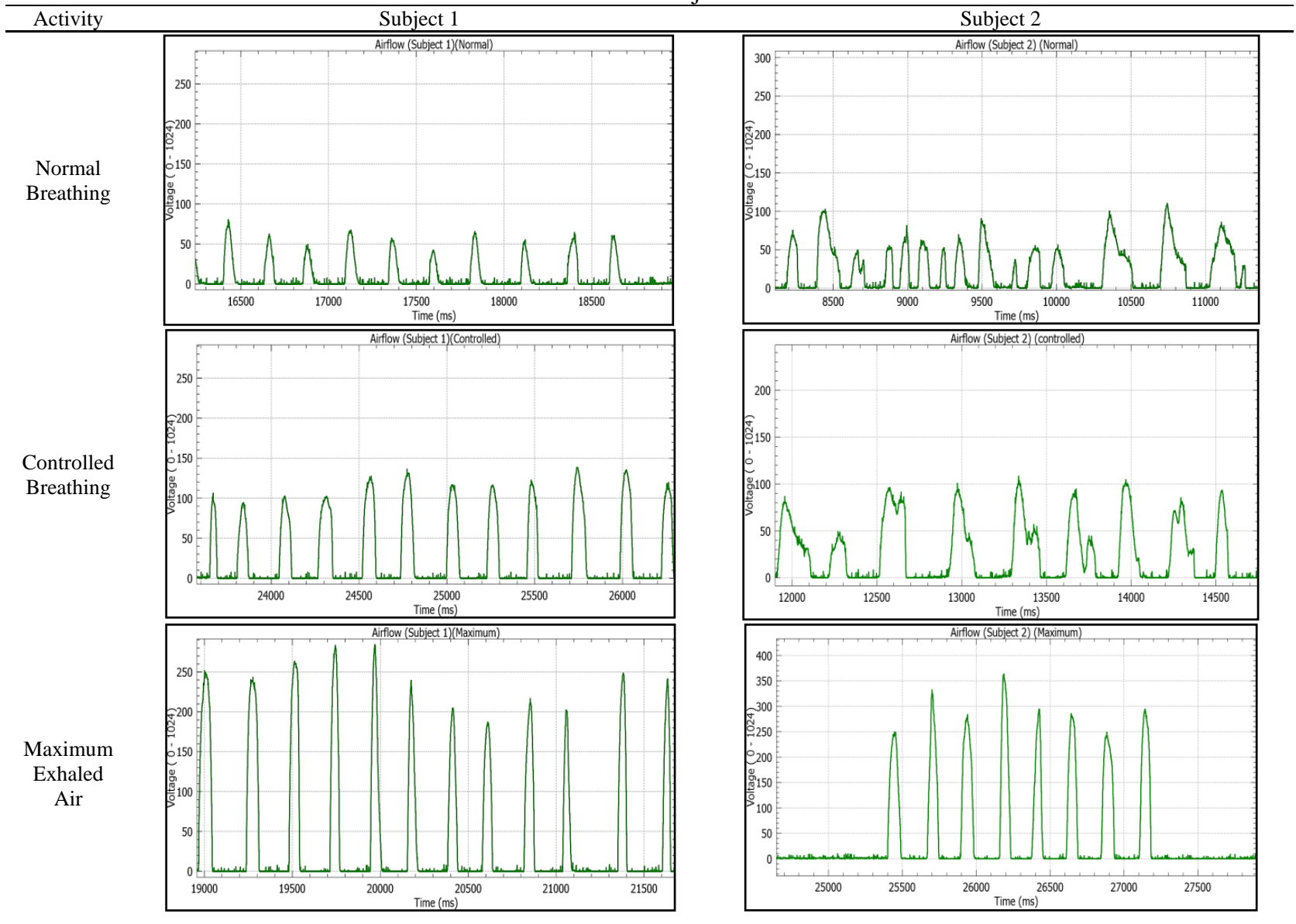


The subject faced three types of activities to observe changes in GSR sensor output in micro-Siemen $(\mu S)$ against time in second (s). In a relaxed state, the subject was advised to be in the most comfortable state before the data was taken. While in forced exhalation, the subject was instructed to inhale deeply and exhale afterwards. The subject saw a short horror video for a surprise test. The result is as depicted in Table 4. During the relaxed state, both graphs show a stable graph, but during the surprise test, the graph line experienced a sudden hike when the subjects were surprised. When removing the sensor from the subject, the reading dropped to $-1 \mu \mathrm{S}$ as programmed in the Arduino software.

The e-Health temperature sensor reading was taken every 10 minutes together with a commercial sensor (MT902C-CU) on a subject in a laboratory environment. The e-Health temperature sensor was calibrated before the experiment was conducted. The calibrated value is as stated in Table 5 while the result is depicted in Table 6. Comparing data taken from both temperature sensors, the differences are between $0.11^{\circ} \mathrm{C}$ to $0.26{ }^{\circ} \mathrm{C}$ which concludes the overall difference in percentage is less than $1 \%$ with the highest difference being $0.81 \%$.

The voltage reading and power for each sensor are tabulated in Table 7. ECG sensor average power is the lowest which is $7.84 \mathrm{~W}$ compared to the highest power consumption, body temperature sensor with value 9.03W. The next highest value is GSR sensor with $8.78 \mathrm{~W}$ followed by Airflow sensor 8.50W.

Table 4. Show the airflow graph of digital voltage output against time (s) for different activities of two different subjects

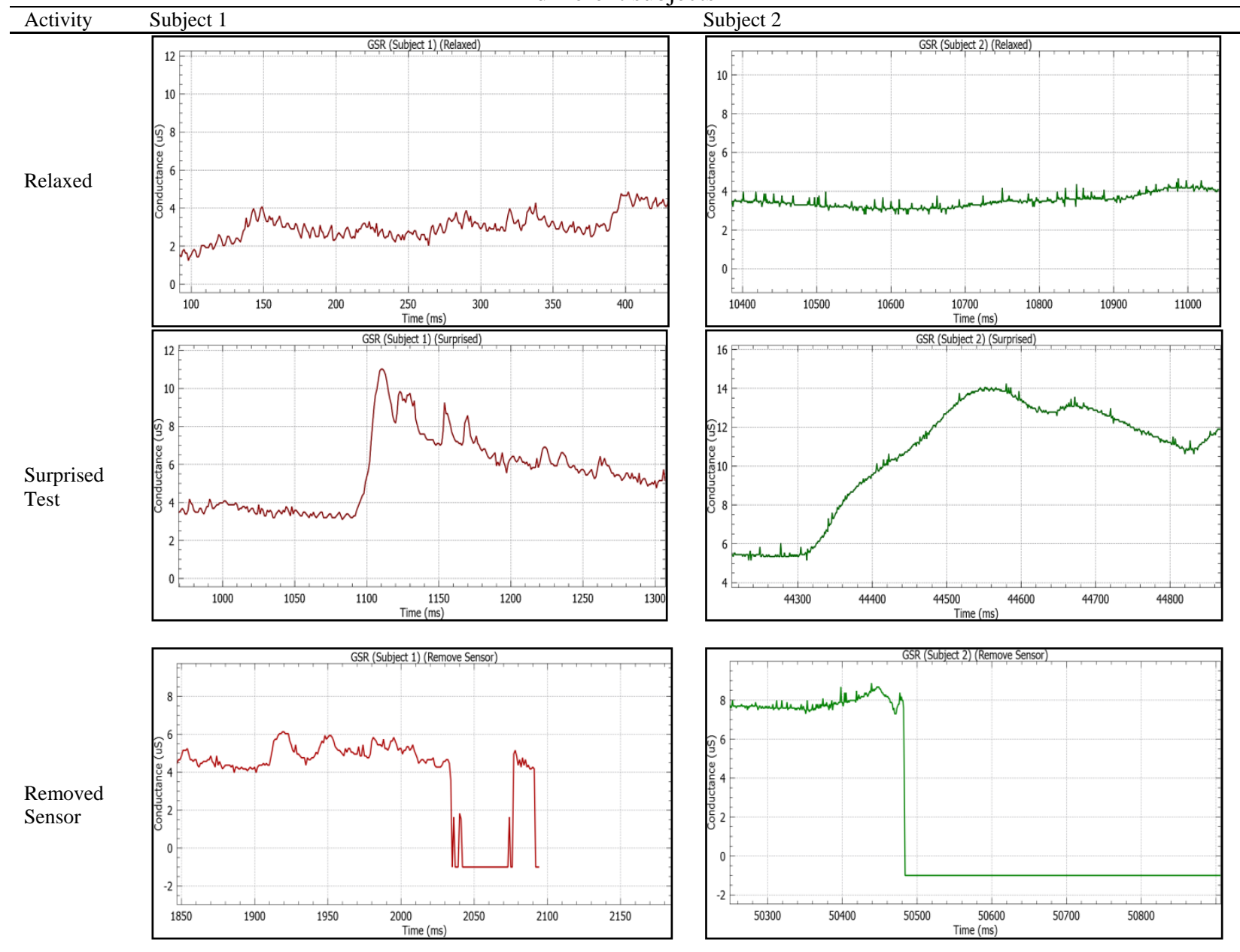

Table 5. Shows the calibration measured from the e-Health shied board

\begin{tabular}{cc}
\hline Measurement & Value \\
\hline Voltage Reference & $2.49 \mathrm{~V}$ \\
$\mathrm{Ra}$ & $4620.0 \Omega$ \\
$\mathrm{Rb}$ & $4680.0 \Omega$ \\
$\mathrm{Rc}$ & $816.0 \Omega$ \\
\hline
\end{tabular}


Table 6. Show the e-Health temperature sensor and commercial sensor data with difference in percentage

\begin{tabular}{ccccc}
\hline $\begin{array}{c}\text { Test } \\
\text { Minute) }\end{array}$ & $\begin{array}{c}\text { Temperature Sensor } \\
\text { e-Health }\left({ }^{\circ} \mathrm{C}\right)\end{array}$ & $\begin{array}{c}\text { Commercial Temperature } \\
\text { Monitor (MT902C-CU) B }\left({ }^{\circ} \mathrm{C}\right)\end{array}$ & $\begin{array}{c}\text { Difference in Measurement } \\
|\mathrm{A}-\mathrm{B}|\left({ }^{\circ} \mathrm{C}\right)\end{array}$ & $\begin{array}{c}\text { Difference percentage } \\
(|\mathrm{A}-\mathrm{B}|) / \mathrm{B} * 100(\%)\end{array}$ \\
\hline 10 & 31.77 & 32.0 & 0.23 & 0.72 \\
20 & 31.74 & 32.0 & 0.26 & 0.81 \\
30 & 32.15 & 32.0 & 0.15 & 0.47 \\
40 & 31.86 & 32.0 & 0.14 & 0.44 \\
50 & 31.89 & 32.0 & 0.11 & 0.34 \\
60 & 32.18 & 32.0 & 0.18 & 0.56 \\
\hline
\end{tabular}

Table 7. Shows each sensor average and peak power consumption

\begin{tabular}{|c|c|c|c|c|c|}
\hline \multirow[t]{2}{*}{ Sensor } & \multicolumn{2}{|c|}{ Voltage (V) } & \multirow[t]{2}{*}{$\operatorname{Resistor}(\Omega)$} & \multicolumn{2}{|c|}{$\begin{array}{c}\text { Power } \\
\mathrm{P}=\mathrm{V}^{2} / \mathrm{R}\end{array}$} \\
\hline & Average & Peak & & Average & Peak \\
\hline$E C G$ & 3.43 & 0.30 & 1.5 & 7.84 & 0.06 \\
\hline Airflow & 3.57 & 0.46 & 1.5 & 8.50 & 0.14 \\
\hline GSR & 3.63 & 0.50 & 1.5 & 8.78 & 0.17 \\
\hline Body Temperature & 3.68 & 046 & 1.5 & 9.03 & 0.14 \\
\hline
\end{tabular}

\section{CONCLUSION}

This paper discussed the available health monitoring system and an e-health monitoring system consist of four different bio-signal sensor ECG, Body Temperature, Airflow and GSR with e-Health shield board and Arduino board as the pre-processing and processing element respectively in the monitoring system. Each sensor tested and the results works accordingly to each experimental test as in Section V. Average power consumption is highest when using body temperature sensor.

\section{ACKNOWLEDGEMENTS}

The author would like to acknowledge the support from the Fundamental Research Grant Scheme (FRGS) under a grant number of FRGS/2/2014/ICT06/UNIMAP/02/3 from the Ministry of Higher Education Malaysia.

\section{REFERENCES}

[1] "WHO|eHealth, " 2016. [Online]. Available: http://www.who.int/topics/ehealth/en/. [Accessed: 22-Oct-2016].

[2] H. R. B, D. Saxena, S. Kumar, G. V Sagar, "Design of a Wearable Remote Neonatal Health, " vol. 1, pp. 34-51.

[3] O. M. Sumathi, M. Malini, T. Vikram, "Wireless Data Acquisition System For Vital Sign Monitoring of Neonates, " pp. 2-5.

[4] L. Mainetti, L. Patrono, A. Secco, and I. Sergi, "An IoT-aware AAL System for Elderly People. "

[5] L. Fanucci, S. Saponara, T. Bacchillone, M. Donati, P. Barba, I. Sánchez-tato, and C. Carmona, "Sensing Devices and Sensor Signal Processing for Remote Monitoring of Vital Signs in CHF Patients, " vol. 62(3), pp. 553-569, 2013.

[6] R. Parker, A. Vitalis, R. Walker, D. Riley, and H. G. Pearce, "Measuring wildland fire fighter performance with wearable technology, " Appl. Ergon., vol. 59, pp. 34-44, 2017.

[7] T. Przybylski, P. Froehle, C. Mcdonald, M. Mirzaee, S. Noghanian, R. Fazel-rezai, A. E. Hardware, "Wearable Wireless Body Area Network for Aeronautical Applications," pp. 563-568, 2015.

[8] K. C. Kavitha, S. M. Ieee, and R. Perumalraja, "Smart Wireless Healthcare Monitoring for Drivers Community, " pp. 1105-1108, 2014.

[9] C. Kulkarni, H. Karhade, and S. Gupta, "Health Companion Device using IoT and Wearable Computing," pp. 152-156, 2016.

[10] E. P. Zeitler and J. P. Piccini, "Remote monitoring of cardiac implantable electronic devices ( CIED ), " Trends Cardiovasc. Med., vol. 26(6), pp. 568-577, 2016.

[11] P. S. Pandian, K. Mohanavelu, K. P. Safeer, T. M. Kotresh, D. T. Shakunthala, P. Gopal, and V. C. Padaki, "Smart Vest: Wearable multi-parameter remote physiological monitoring system, " vol. 30, pp. 466-477, 2008.

[12] B. Massot, S. Member, C. Gehin, R. Nocua, S. Member, A. Dittmar, E. Mcadams, and S. Member, "A wearable, lowpower, health-monitoring instrumentation based on a Programmable System-on-Chip," pp. 4852-4855, 2009.

[13] V. P. Rachim, W. Chung, "Wearable Noncontact Armband for Mobile ECG Monitoring System," vol. 10(6), pp. 1112-1118, 2016.

[14] K. M. Al-aubidy, A. M. Derbas, and A. W. Al-mutairi, "Real-Time Patient Health Monitoring and Alarming Using Wireless-Sensor-Network," pp. 416-423.

[15] S. R. Gouravajhala, L. Khuon, "A Multi-Modality Sensor Platform Approach to Detect Epileptic Seizure Activity, " pp. 233-234, 2012.

[16] T. Sharma, B. Kapoor, "Intelligent Data Analysis Algorithms on Biofeedback Signals for Estimating Emotions, " pp. 335-340, 2014. 
[17] H. Ying, M. Schl, A. Schnitzer, T. Sch, M. E. Schl, S. Leonhardt, M. Schiek, "Distributed Intelligent Sensor Network for the Rehabilitation of Parkinson 's Patients," vol. 15(2), pp. 268-276, 2011.

[18] L. Frenzel, "What's the Difference Between SAR and Delta-Sigma ADCs?," 2016. [Online].Available: http://electronicdesign.com/adc/what-s-difference-between-sar-and-delta-sigma-adcs.

[19] Cooking-hacks.com, "e-Health Sensor Platform V2.0 for Arduino and Raspberry Pi [Biometric / Medical Applications]," 2016. [Online].

[20] Arduino.cc, "Arduino-Arduino Board Uno," 2016. [Online]. Available: https://www.arduino.cc/en/Main/ArduinoBoardUno. [Accessed: 01-Oct-2016].

[21] "Realterm: Serial Terminal," Realterm.sourcefog.io. [Online]. Available: https://realterm.sourceforge.io/. [Accessed: 22-Oct-2016].

[22] "Kst - Visualize your data," Kst-plot.kde.org. [Online]. Available: https://kst-plot.kde.org/. [Accessed: 22-Oct-2016].

[23] A. Ekhare, "Design and Development of Multi-parameter Patient Monitoring System with Wireless Communication to," pp. 21-25, 2014.

[24] "Difference between 8 bit and 16 bit Microcontroller." [Online]. Available: Difference between 8 bit and 16 bit Microcontroller.

[25] IMOTION, Everything you need to know about Galvanic Skin Response to push your insights into emotional behavior - 1 -. 2016.

\section{BIOGRAPHIES OF AUTHORS}

\begin{tabular}{|l|l|}
\hline & $\begin{array}{l}\text { Nur Athilah Bt. Abdul Rahman graduated for her first degree in Bachelor of Engineering } \\
\text { in Electronics from Universiti Malaysia Perlis (UniMAP) in 2015. Now, she is currently } \\
\text { pursuing her Master Degree by research on signal analysis algorithm and architecture } \\
\text { for health monitoring application. }\end{array}$ \\
\hline & $\begin{array}{l}\text { Associate Professor Dr. Asral Bahari Jambek is a member of the School of } \\
\text { Microelectronics Engineering, Universiti Malaysia Perlis (UniMAP), and was a } \\
\text { Programme Chairperson for the Electronics Engineering Degree Programme, UniMAP. } \\
\text { He has more than 15 years experience in integrated circuit and system design in both the } \\
\text { industry and academic sectors, and has been involved at various levels of VLSI design } \\
\text { such as transistor modelling, digital circuit design, analogue circuit design, logic } \\
\text { synthesis and physical place and route, architecture design and algorithm development. }\end{array}$ \\
\hline
\end{tabular}

